\author{
Marquette University \\ e-Publications@Marquette
}

2006

\title{
Thermal and Flame Properties of Polyethylene and Polypropylene Nanocomposites Based on an Oligomerically-Modified Clay
}

Jinguo Zhang

Marquette University

David D. Jiang

Marquette University

Charles A. Wilkie

Marquette University, charles.wilkie@marquette.edu

Follow this and additional works at: https://epublications.marquette.edu/chem_fac

Part of the Chemistry Commons

\section{Recommended Citation}

Zhang, Jinguo; Jiang, David D.; and Wilkie, Charles A., "Thermal and Flame Properties of Polyethylene and Polypropylene Nanocomposites Based on an Oligomerically-Modified Clay" (2006). Chemistry Faculty Research and Publications. 108.

https://epublications.marquette.edu/chem_fac/108 
Marquette University

\title{
e-Publications@Marquette
}

\section{Chemistry Faculty Research and Publications/College of Arts and Sciences}

This paper is NOT THE PUBLISHED VERSION; but the author's final, peer-reviewed manuscript. The published version may be accessed by following the link in th citation below.

Polymer Degradation and Stability, Vol. 91, No. 2 (February 2006): 298-304. DOI. This article is (C) Elsevier and permission has been granted for this version to appear in e-Publications@Marquette. Elsevier does not grant permission for this article to be further copied/distributed or hosted elsewhere without the express permission from Elsevier.

\section{Thermal and Flame Properties of Polyethylene and Polypropylene Nanocomposites Based on An Oligomerically- Modified Clay}

Jinguo Zhang

Department of Chemistry, Marquette University, Milwaukee, WI

David D. Jiang

Department of Chemistry, Marquette University, Milwaukee, WI

Charles A. Wilkie

Department of Chemistry, Marquette University, Milwaukee, WI

\begin{abstract}
An oligomerically-modified clay was made using a surfactant which is the ammonium salt of an oligomer. The newly modified clay contains $37.5 \%$ inorganic clay and $62.5 \%$ oligomer. Polyethylene and polypropylene nanocomposites were made by melt blending the polymer with the oligomericallymodified clay in a Brabender mixer at various clay loadings. The structure of the nanocomposites was characterized by X-ray diffraction and transmission electron microscopy. Mechanical testing showed that the polyethylene nanocomposites had an enhanced Young's modulus and slightly decreased elongation, while the changes for polypropylene nanocomposites are small compared with the virgin
\end{abstract}


polymers. The thermal stability and flame properties were evaluated using thermogravimetric analysis and cone calorimetry, respectively. The plasticising effect of the oligomer was suppressed because of the increased inorganic content. The maximum reduction in peak heat release rate is about $40 \%$.

\section{Keywords}

Fire retardancy, Nanocomposites, Oligomerically modified

\section{Introduction}

Since the great advantages of polyamide-6-clay nanocomposites were first observed ${ }^{[1]}$, much work has been carried out on polymer-clay nanocomposites ${ }^{[2]}$. It is a challenge to make polyethylene (PE) and polypropylene (PP) because of their non-polarity. Much research has focused on the use of maleic anhydride grafted PE or PP as a compatibiliser [3], [4], [5] through melt blending with organically-modified clay while others have used new catalysts through in situ polymerisation ${ }^{[6]}$. Recent work from this laboratory has shown that both polyethylene and polypropylene nanocomposites could be formed by direct melt blending polymer with an oligomerically-modified clay [7], [8], [9], [10]. Typically, the oligomerically-modified clays contain $25 \%$ inorganic clay and $75 \%$ oligomer but a variation in the oligomer content can lead to more advantageous behaviour on some properties.

With $5 \%$ inorganic clay loading, the best result of reduction in peak heat released rate (PHRR) for PE and PP nanocomposites is $60 \%$. The clay used in that case, known as triclay, was prepared from an oligomeric surfactant, which is an ammonium salt of the terpolymer from vinylbenzyl chloride (VBC), styrene (St) and lauryl acrylate. The disadvantage of using this oligomeric surfactant containing lauryl acrylate is its ability to plasticise the polymer. When $5 \%$ inorganic clay is introduced into the system, $15 \%$ oligomer will be introduced into the system at the same time. The Young's modulus and tensile strength of the nanocomposites usually decrease, which is opposite to that of nanocomposites based on the typical organically-modified clay.

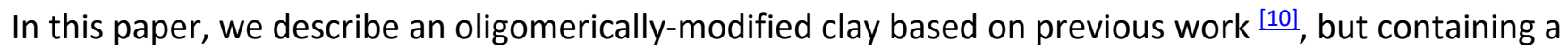
higher amount of inorganic clay. The modified clay is melt blended with PE and PP in a Brabender mixer. The PE nanocomposites show enhanced Young's modulus and slightly decreased elongation, while the change for PP nanocomposites are small compared with virgin PP.

\section{Experimental}

\subsection{Materials}

Low-density polyethylene (melt index $190^{\circ} \mathrm{C} / 2.16 \mathrm{~kg}, 7 \mathrm{~g} / 10 \mathrm{~min}$ ) and isotactic polypropylene (melt index $230{ }^{\circ} \mathrm{C} / 2.16 \mathrm{~kg}, 4 \mathrm{~g} / 10 \mathrm{~min}$ ) were acquired from the Aldrich Chemical Company; vinylbenzyl chloride (VBC), styrene (St), lauryl acrylate and 2,2'-azobisisobutyronitrile (AIBN) were also from Aldrich. Sodium montmorillonite was provided by Southern Clay Products, Inc.

\subsection{Synthesis of VBC, St and lauryl acrylate copolymer and its ammonium salt}

The procedure is the same as has been reported $[10]$ except that the amount of vinylbenzyl chloride is doubled. A solution was prepared containing $115.2 \mathrm{~g}(0.48 \mathrm{~mol})$ portion of lauryl acrylate, $50.0 \mathrm{~g}$ (0.48 mol) styrene and $18.4 \mathrm{~g}(0.12 \mathrm{~mol})$ vinylbenzyl chloride in $400 \mathrm{ml}$ THF in a $1000 \mathrm{ml} 3$ neck round bottom flask, equipped with a magnetic stirrer and a condenser. The solution was first stirred for $10 \mathrm{~min}$ then gently refluxed under nitrogen for $10 \mathrm{~min}$. To this solution was added $9.8 \mathrm{~g}(60 \mathrm{mmol})$ 
AIBN in one portion. The system was kept at a gentle reflux for $12 \mathrm{~h}$. The copolymer was precipitated with a large amount of methanol. A $160 \mathrm{~g}$ portion of a colourless copolymer was collected after filtration. ${ }^{1} \mathrm{H}$ NMR: $\left(\mathrm{CDCl}_{3}, \mathrm{ppm}\right) 7.1(\mathrm{br}, 17 \mathrm{H}), 6.7(\mathrm{br}, 12 \mathrm{H}), 4.5(\mathrm{br}, 2 \mathrm{H}), 3.8(\mathrm{br}, 10 \mathrm{H}), 2.2(\mathrm{br}, 11 \mathrm{H})$, 1.9(br, 22H), 1.6(br, 10H), 1.3(br, 90H), 0.9(t, 15H).

For the synthesis of the ammonium salt of the copolymer, a large excess amount of triethylamine was added to a solution of $160 \mathrm{~g}$ copolymer in $500 \mathrm{ml} \mathrm{THF}$ in a $1000 \mathrm{ml}$ round bottom flask. The solution was stirred at room temperature for $2 \mathrm{~h}$ then kept at gentle reflux for another $10 \mathrm{~h}$ under nitrogen. The solvent was evaporated at $70{ }^{\circ} \mathrm{C}$ under vacuum and $170 \mathrm{~g}$ copolymer was collected. A new broad peak in the NMR spectrum at 3.4 ppm may be assigned as the methylene group attached to the nitrogen of the ammonium salt. The methyl group adjacent to the methylene is in the $1.3 \mathrm{ppm}$ region.

\subsection{Preparation of triclay II}

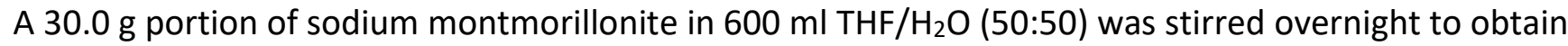
a well-dispersed suspension while $50.0 \mathrm{~g}$ of the copolymer salt was dissolved in $250 \mathrm{ml} \mathrm{THF}$. A $200 \mathrm{ml}$ portion of the salt solution was slowly added to the dispersed clay and the system was vigorously stirred for $12 \mathrm{~h}$, then the remaining portion of the salt solution was added drop-wise with stirring. A precipitate quickly settled to the bottom of the flask after stirring was stopped, and the supernatant liquid was poured off, then another $500 \mathrm{ml}$ portion of $\mathrm{THF} / \mathrm{H}_{2} \mathrm{O}$ (50:50) was added and stirring was continued for an additional $2 \mathrm{~h}$. Finally, the precipitate was collected and dried in a vacuum oven at $80^{\circ} \mathrm{C}$ for $24 \mathrm{~h}$ and $80 \mathrm{~g}$ of oligomerically-modified clay, triclay II, was obtained.

\subsection{Preparation of polymer-clay nanocomposites}

All nanocomposites were prepared using melt blending in a Brabender Plasticorder at $60 \mathrm{rpm}$ and $185^{\circ} \mathrm{C}$ for $5 \mathrm{~min}$; the calculated amount of polymer and triclay II was put into the Brabender mixer at the same time. After $5 \mathrm{~min}$ of blending, the mixture was removed from the chamber and allowed to cool to room temperature. The composition of the nanocomposites is given in Table 1.

Table 1. Composition of polymer clay nanocomposites

\begin{tabular}{|l|l|l|l|}
\hline No. & PE or PP & Triclay II & Inorganic clay loading (\%) \\
\hline 1 & 97 & 3 & 1.1 \\
\hline 2 & 92 & 8 & 3.0 \\
\hline 3 & 88 & 12 & 4.5 \\
\hline
\end{tabular}

\subsection{Instrumentation}

X-ray diffraction (XRD) measurements were performed on a Rigaku Geiger Flex, 2-circle powder diffractometer equipped with Cu-K $\alpha$ generator $(\lambda=1.5404 \AA)$ at $1 \mathrm{~kW}$, scanning from 1 to $10^{\circ}$ at 0.1 step; generator tension was $50 \mathrm{kV}$ at a current of $20 \mathrm{~mA}$. All the samples were compression molded into $20 \mathrm{~mm} \times 15 \mathrm{~mm} \times 1 \mathrm{~mm}$ plaques for XRD measurements. Bright field transmission electron microscopy (TEM) images were obtained at $120 \mathrm{kV}$, at low-dose conditions, with a Phillips 400T electron microscopy. The sample was ultramicrotomed with a diamond knife on a Leica Ultracut UCT microtome to give 70-nm-thick section. The section was transferred from water to carbon-coated $\mathrm{Cu}$ grids of $\mathbf{2 0 0}$ mesh. The contrast between the layered silicate and the polymer phase was sufficient for imaging, so no heavy metal staining of sections prior to imaging was required. Thermogravimetric analysis, TGA, was carried out on an SDT 2960 unit under nitrogen at a scan rate of $20^{\circ} \mathrm{C}$ per minute from room temperature to $600{ }^{\circ} \mathrm{C}$ at $15 \mathrm{mg}$ scale. Temperatures are reproducible to $\pm 3{ }^{\circ} \mathrm{C}$ while the fraction of non-volatile is repeatable to $\pm 2 \%$. Cone calorimetry was performed on an Atlas CONE-2 according to ASTM E 1354 at an incident flux of $35 \mathrm{~kW} / \mathrm{m}^{2}$ using a cone shaped heater. Exhaust flow 
was set at $24 \mathrm{l} / \mathrm{s}$ and the spark was continuous until the sample ignited. Cone samples were prepared by compression moulding the composites into $100 \mathrm{~mm} \times 100 \mathrm{~mm} \times 3 \mathrm{~mm}$ square plaques. Typical results from cone calorimetry are reproducible to within about $\pm 10 \%$. These uncertainties are based on many runs in which thousands of samples have been combusted $[11]$. Tensile properties were measured using MTS Alliance RT/5 tensile test machine at a crosshead speed of $25.4 \mathrm{~mm} / \mathrm{min}$. The reported values are based on the average of 5 determinations.

\section{Results and discussion}

The clay used in this study, triclay II, is sodium montmorillonite modified with an oligomeric surfactant, which is an ammonium salt of a random copolymer. The reactive site of the copolymer is from vinylbenzyl chloride. Comparing the surfactant used in this study with that previously used, triclay, the amount of vinylbenzyl chloride used to synthesize the new surfactant is doubled. Triclay contains $25 \%$ inorganic clay and $75 \%$ oligomer surfactant $\stackrel{[10]}{ }$, while triclay II contains $37.5 \%$ inorganic clay, as will be shown from the TGA analysis.

\subsection{Characterization of the clay and its nanocomposites by XRD}

The XRD pattern of the triclay II is shown in Fig. 1; this is the same pattern that was seen for triclay $\frac{[10]}{\text {. }}$ The [001] reflection of the clay is located at $2.4^{\circ}$, which gives a d-spacing of $3.7 \mathrm{~nm}$. In this study, $1.1 \%$, $3.0 \%$ and $4.5 \%$ inorganic clay loadings were investigated. Because this clay contains $37.5 \%$ inorganic clay, the corresponding amounts of oligomerically-modified clay that were used are $3 \%, 8 \%$, and $12 \%$. The XRD traces of PE and PP nanocomposites are shown in Fig. 2, Fig. 3, respectively. All the nanocomposites exhibit a strong reflection at $2.4^{\circ}$, which is the same as that of the clay. The same lack of change in the d-spacing has been observed with triclay ${ }^{[10]}$; either no polymer inserts between the clay layers and an immiscible system is obtained or the $d$-spacing is already sufficiently large to permit the entry of the polymer without increasing the d-spacing. Transmission electron microscopy (TEM) is necessary to answer this question.

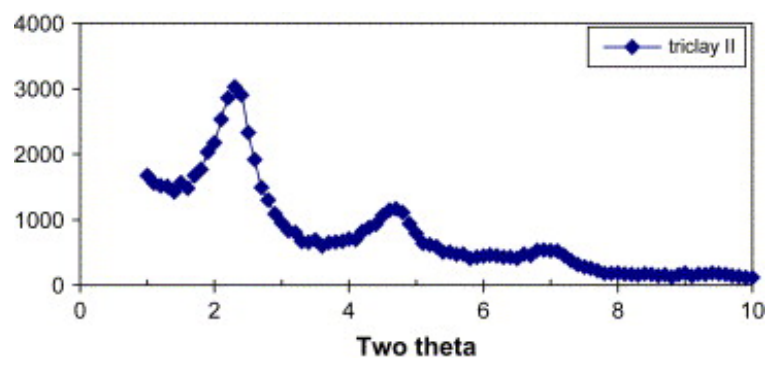

Fig. 1. X-ray diffraction pattern of the oligomerically-modified clay.

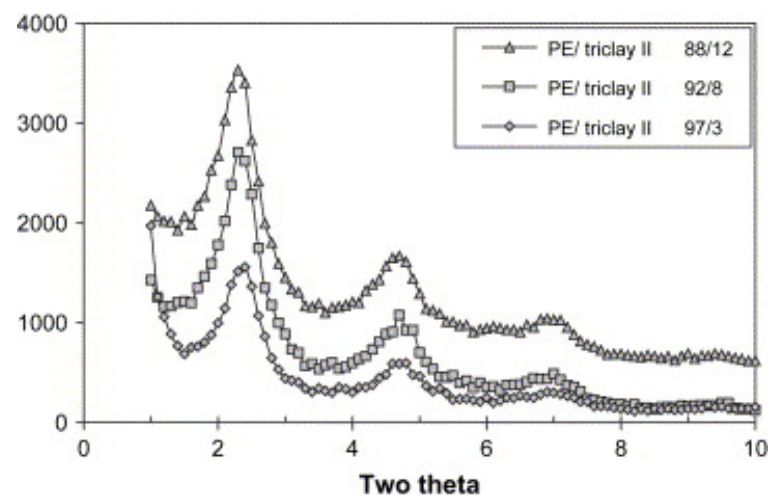

Fig. 2. X-ray diffraction traces of polyethylene-clay nanocomposites. 


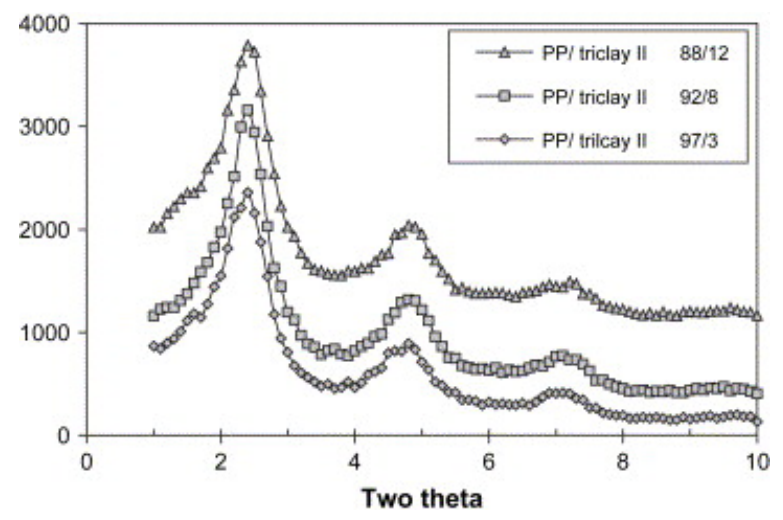

Fig. 3. X-ray diffraction traces of polypropylene-clay nanocomposites.

\subsection{Characterization of the nanocomposites by TEM}

TEM images were obtained for both polyethylene and polypropylene nanocomposites at $4.5 \%$ inorganic clay loads and these images are shown in Fig. 4, Fig. 5, respectively. In the low magnification images, one can see that reasonably good dispersion of the clay in the polymer has been obtained. In the high magnification images, an intercalated structure can be deduced for both PE and PP nanocomposites. Thus, these are best described as intercalated nanocomposites.
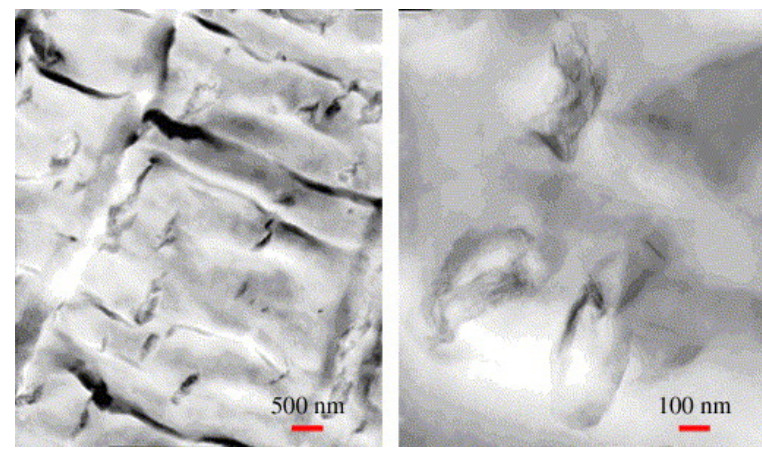

Fig. 4. TEM images of PE-clay nanocomposite at $4.5 \%$ inorganic clay loading.

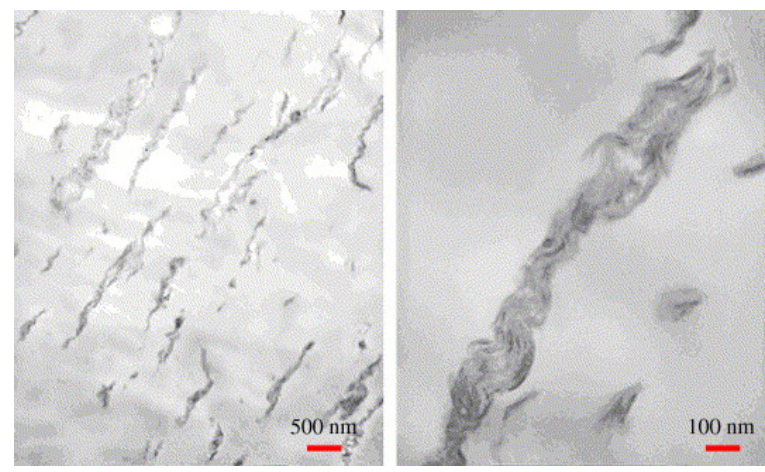

Fig. 5. TEM images of PP-clay nanocomposite at $4.5 \%$ inorganic clay loading.

\subsection{TGA characterization of nanocomposites}

TGA data for clay and its nanocomposites are collected in Table 2 and shown graphically in Fig. 6 for the clay alone, and Fig. 7, Fig. 8 for the PE and PP nanocomposites, respectively. The parameters listed are the onset temperature of the degradation, usually taken as the temperature at which $10 \%$ degradation occurs, $T_{0.1}$, the mid-point of the degradation, $T_{0.5}$, another indication of thermal stability and the non-volatile residue found at $600^{\circ} \mathrm{C}$, denoted as char. The non-volatile fraction for modified 
clay is $37.5 \%$ at $600{ }^{\circ} \mathrm{C}$, indicating the inorganic content. The $10 \%$ mass loss temperature of the clay is $350{ }^{\circ} \mathrm{C}$ and $50 \%$ mass loss temperature is $418^{\circ} \mathrm{C}$ indicating that triclay II has a similar thermal stability as triclay $\stackrel{[10]}{ }$; the decreased organic content does not have an effect on the thermal stability.

Table 2. TGA data, in nitrogen, for polyethylene and polypropylene-clay nanocomposites

\begin{tabular}{|l|l|l|l|l|}
\hline & Triclay II & $\boldsymbol{T}_{\mathbf{0 . 1}}\left({ }^{\circ} \mathbf{C}\right)$ & $\mathbf{T}_{\mathbf{0 . 5}}\left(^{\circ} \mathbf{C}\right)$ & Char at $600^{\circ} \mathbf{C}(\%)$ \\
\hline$P E$ & & & & \\
\hline 100 & 0 & 436 & 475 & 0 \\
\hline 97 & 3 & 463 & 488 & 2 \\
\hline 92 & 8 & 456 & 492 & 4 \\
\hline 88 & 12 & 431 & 492 & 5 \\
\hline$P P$ & & & & \\
\hline 100 & 0 & 400 & 449 & 0 \\
\hline 97 & 3 & 431 & 467 & 2 \\
\hline 92 & 8 & 441 & 472 & 3 \\
\hline 88 & 12 & 441 & 472 & 5 \\
\hline 0 & 100 & 350 & 418 & 37.5 \\
\hline
\end{tabular}

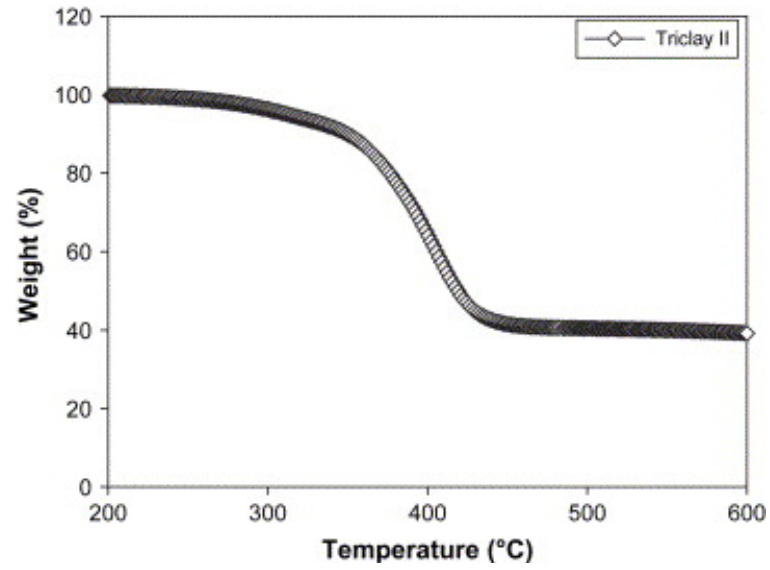

Fig. 6. TGA curve for the clay in nitrogen.

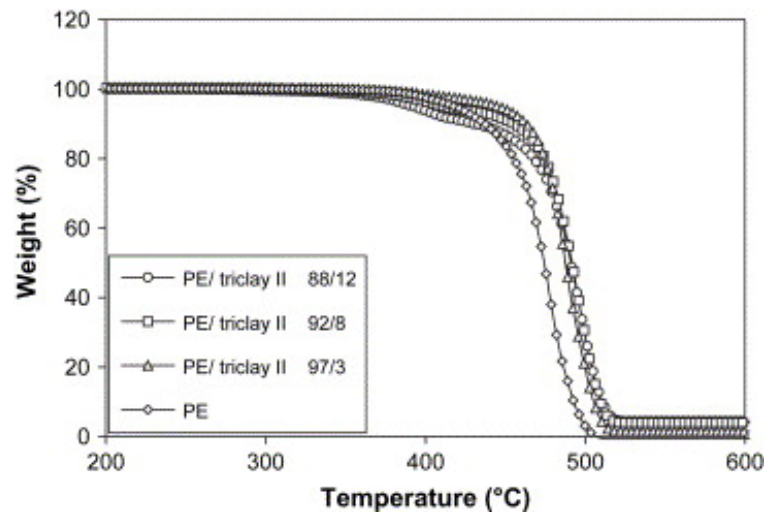

Fig. 7. TGA curves for PE-clay nanocomposites in nitrogen. 


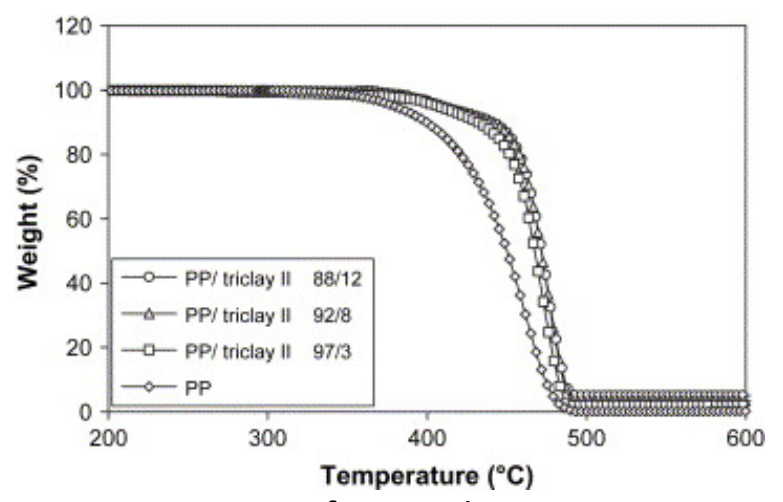

Fig. 8. TGA curves for PP-clay nanocomposites in nitrogen.

The onset temperature of polyethylene is around $90^{\circ} \mathrm{C}$ higher than that of triclay II, so one might expect an earlier onset temperature for the polyethylene nanocomposites than in the virgin polymer. The nanocomposites contain $3 \%$ and $8 \%$ triclay II actually show an onset temperature which is $20{ }^{\circ} \mathrm{C}$ higher than that in polyethylene. When the loading of triclay II reaches $12 \%$, the onset temperature is $5{ }^{\circ} \mathrm{C}$ lower than that of PE itself, which means the oligomer begins to have an influence on the degradation at this level. The mid-point of the degradation, $T_{0.5}$, of all the PE nanocomposites is about $25^{\circ} \mathrm{C}$ higher than that of virgin PE even though the mid-point for the clay is $57^{\circ} \mathrm{C}$ lower than that of PE. The amount of char that is formed at $600^{\circ} \mathrm{C}$ corresponds rather well to the inorganic clay loading in the system.

PP nanocomposites show enhanced thermal stabilities in all case. The onset temperature increases by $31{ }^{\circ} \mathrm{C}$ at $3 \%$ clay loading, while the mid-point temperature increases by $28^{\circ} \mathrm{C}$. At higher clay loadings, $8 \%$ and $12 \%$, the onset temperature of the nanocomposites is $41{ }^{\circ} \mathrm{C}$ higher than that of PP and the increase for the mid-point temperature is $23^{\circ} \mathrm{C}$, which should be again assigned to the nanocomposite effect.

\subsection{Cone calorimetry}

The fire properties of materials can be evaluated using cone calorimeter. The most important parameters from cone calorimetry are the heat release rate, and especially its peak value, (PHRR); the time to ignition $\left(t_{\text {ign }}\right)$; the mass loss rate, MLR, which usually tracks very well with the peak heat release rate; the specific extinction area (SEA), a measure of the amount of smoke produced; and the total heat released (THR).

The heat release rate curves for the virgin polymers and their nanocomposites are shown graphically in Fig. 9, Fig. 10 and the corresponding data are given in Table 3. PE and PP nanocomposites have similar behaviour at the same clay loading. The peak heat release rates of the nanocomposites that contains $3 \%$ clay (1.1\% inorganic clay) show a small reduction compared with the virgin polymers. When the loading of clay reaches $8 \%$ ( $3 \%$ inorganic clay), both PE and PP nanocomposites show about $30 \%$ reduction in PHRR. At a clay loading of $12 \%$ (4.5\% inorganic clay), the reduction in PHRR is around $40 \%$. The reduction in the mass loss rate is roughly proportional to the reduction in the peak heat release rate. The reduction in the PHRR is less for triclay II than for the previously examined triclay $\frac{[10]}{}$. Since there is a correlation between reduction in the PHRR and the quality of nanodispersion [11], [12], [13], this is an indication that better nano-dispersion has been obtained with the clay with a higher organic content, which should not be a surprise since an increased organic content must make for better compatibility. The TEM images also show better nano-dispersion for triclay $\stackrel{[10]}{\text { than for }}$ 
the clay used in this study. There is no change in the total heat released for any of these nanocomposites compared with the virgin polymers, which is the usual observation for nanocomposites. The change in the time to ignition $\left(t_{\text {ign }}\right)$ for the PE nanocomposites is small, while there is essentially no change for PP nanocomposites. The amount of smoke gradually increases as the clay loading increases, which has been observed in previous work. There is an obvious explanation for the difference between the two versions of triclay. The clay used in this study, triclay II, was prepared using a much higher content of vinylbenzyl chloride, which means that there will be many more ammonium cations on the clay and thus the opportunity for the pinning of the clay layers together is greatly increased. It is clear from the TEM and the data from cone calorimetry that pinning is much more likely to occur with the clay under study herein and this is the likely explanation for the poorer nano-dispersion in this case.

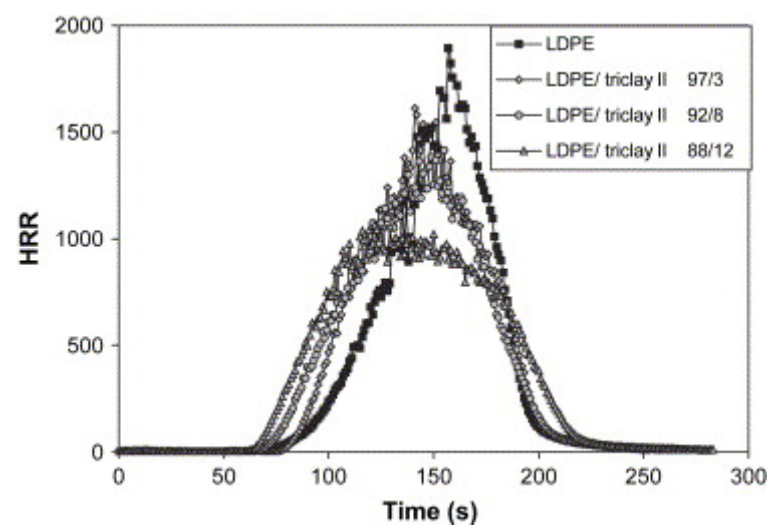

Fig. 9. Comparison of the heat release rate (HRR) plots for pure PE and its clay nanocomposites at $35 \mathrm{~kW} / \mathrm{m}^{2}$ heat flux.

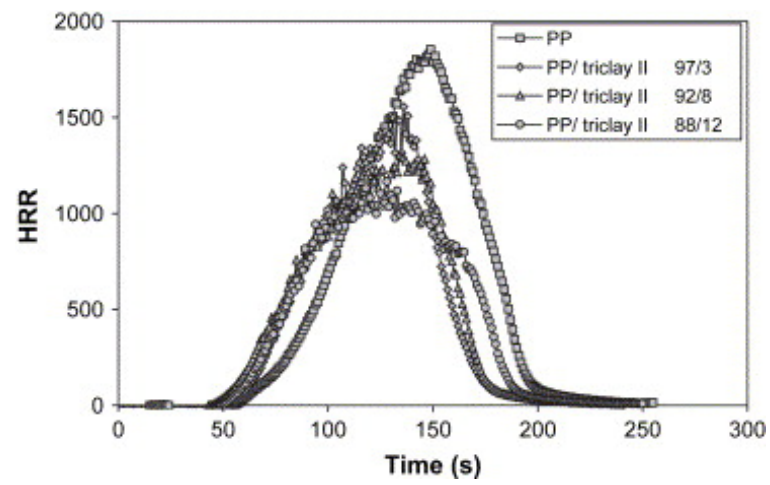

Fig. 10. Comparison of the heat release rate (HRR) plots for pure PP and its clay nanocomposites at $35 \mathrm{~kW} / \mathrm{m}^{2}$ heat flux.

Table 3. Cone calorimetric data for polyethylene, polypropylene and their nanocomposites

\begin{tabular}{|c|c|c|c|c|c|c|}
\hline & $\begin{array}{l}\text { Triclay } \\
\text { II }\end{array}$ & $t_{\text {ign }}{ }^{\mathrm{a}}(\mathrm{s})$ & $\begin{array}{l}\text { PHRR }^{a}\left(\mathrm{~kW} / \mathrm{m}^{2}\right)(\% \\
\text { reduction) }\end{array}$ & $\mathrm{SEA}^{\mathrm{a}}\left(\mathrm{m}^{2} / \mathrm{kg}\right)$ & $\mathrm{MLR}^{\mathrm{a}}\left(\mathrm{g} / \mathrm{sm}^{2}\right)$ & $\operatorname{THR}^{a}\left(\mathrm{MJ} / \mathrm{m}^{2}\right)$ \\
\hline \multicolumn{7}{|l|}{$P E$} \\
\hline 100 & 0 & $71 \pm 3$ & $1892 \pm 95$ & $357 \pm 16$ & $29 \pm 0$ & $99 \pm 2$ \\
\hline 97 & 3 & $75 \pm 3$ & $1614 \pm 146(15)$ & $446 \pm 41$ & $26 \pm 3$ & $99 \pm 5$ \\
\hline 92 & 8 & $72 \pm 4$ & $1415 \pm 44(25)$ & $463 \pm 22$ & $24 \pm 0$ & $100 \pm 1$ \\
\hline 88 & 12 & $64 \pm 3$ & $1044 \pm 58(45)$ & $554 \pm 5$ & $20 \pm 1$ & $99 \pm 1$ \\
\hline$P P$ & & & & & & \\
\hline
\end{tabular}




\begin{tabular}{|l|l|l|l|l|l|l|}
\hline 100 & 0 & $52 \pm 0$ & $1897 \pm 44$ & $56 \pm 13$ & $25 \pm 1$ & $101 \pm 1$ \\
\hline 97 & 3 & $48 \pm 3$ & $1577 \pm 92(17)$ & $588 \pm 25$ & $25 \pm 0$ & $95 \pm 3$ \\
\hline 92 & 8 & $49 \pm 4$ & $1309 \pm 8(31)$ & $607 \pm 28$ & $23 \pm 1$ & $97 \pm 2$ \\
\hline 88 & 12 & $52 \pm 5$ & $1160 \pm 51(40)$ & $644 \pm 31$ & $21 \pm 2$ & $93 \pm 1$ \\
\hline
\end{tabular}

${ }^{\mathrm{a}} t_{\text {ign, }}$, Time to ignition; PHRR, peak heat release rate; \% reduction = [PHRR (virgin) - PHRR (nano)]/PHRR (virgin); SEA, specific extinction area; MLR, mass loss rate; THR, total heat released.

\subsection{Mechanical properties}

The mechanical properties of the nanocomposites, such as tensile strength, Young's modulus and elongation at break, have been evaluated and the data are presented in Table 4 . In both PE and PP nanocomposites, the tensile strength is slightly decreased compared with the virgin polymers, while Young's modulus is slightly increased. From previous work with the higher organic content clay, a plasticising effect was observed, leading to a decrease in all aspects of the mechanical properties. Here, the increased inorganic content causes a diminishing of this plasticisation. The elongation at break for PE nanocomposites drops from $418 \%$ to $250 \%$ when clay loading increases to $12 \%$, while the change for PP nanocomposites is negligible.

Table 4. Tensile properties of PE, PP and their nanocomposites

\begin{tabular}{|l|l|l|l|l|}
\hline & Triclay II & Tensile strength (MPa) & Modulus (MPa) & Elongation (\%) \\
\hline$P E$ & & & & \\
\hline 100 & 0 & 12 & 162 & 418 \\
\hline 97 & 3 & 10 & 194 & 352 \\
\hline 92 & 8 & 8 & 215 & 268 \\
\hline 88 & 12 & 9 & 210 & 250 \\
\hline$P P$ & & & & \\
\hline 100 & 0 & 35 & 875 & 655 \\
\hline 97 & 3 & 30 & 864 & 523 \\
\hline 92 & 8 & 28 & 842 & 478 \\
\hline 88 & 12 & 30 & 894 & 584 \\
\hline
\end{tabular}

\section{Conclusions}

Clay is modified by cationic exchange with an oligmeric surfactant, which contains a long alkyl group and a benzene ring. In order to suppress the plasticising effect that has been previously observed, the inorganic content in this oligomerically-modified clay is increased to $37.5 \%$. The modified clay was directly melt blended with polyethylene and polypropylene, which led to enhanced thermal stability for the nanocomposites compared with the virgin polymers. The increased Young's modulus for the nanocomposites indicates that the increased inorganic clay content has a significant effect on the mechanical properties. On the other hand, these nanocomposites do not show the same level of nanodispersion, which leads to a smaller reduction in the peak heat release rate. The poorer nanodispersion is no doubt due to the increased content of vinylbenzyl chloride, which leads to an increased content on ammonium salts and hence to the pinning of the clays layers. The balance of properties is an important aspect of nanocomposite research and if one changes the surfactant it may have an advantageous effect on some property and a disadvantageous effect on other properties. 


\section{References}

[1] A. Usuki, M. Kawasumi, Y. Kojima, A. Okada, T. Kurauchi, O. Kamigaito. J Mater Res, 8 (1993), pp. 1174-1178

[2] M. Alexandre, P. Dubois. Mater Sci Eng, R28 (2000), pp. 1-63

[3] C.M. Koo, H.T. Ham, S.O. Kim, K.H. Wang, I.J. Chung. Macromolecules, 35 (2002), pp. 5116-5122

[4] G. Liang, J. Xu, S. Bao, W. Xu. J Appl Polym Sci, 91 (2004), pp. 3974-3980

[5] P. Svoboda, C. Zeng, H. Wang, L.J. Lee, D.L. Tomasko. J Appl Polym Sci, 85 (2002), pp. 1562-1570

[6] L. Wei, T. Tang, B. Huang. J Polym Sci Part A Polym Chem, 42 (2004), pp. 941-949

[7] S. Su, D.D. Jiang, C.A. Wilkie. Polym Degrad Stab, 84 (2004), pp. 269-277

[8] S. Su, D.D. Jiang, C.A. Wilkie. Polym Degrad Stab, 84 (2004), pp. 279-288

[9] S. Su, D.D. Jiang, C.A. Wilkie. Polym Degrad Stab, 83 (2004), pp. 333-346

[10] Zhang J, Jiang DD, Wilkie CA. Thermochim Acta, in press.

[11] J.W. Gilman, T. Kashiwagi, M. Nyden, J.E.T. Brown, C.L. Jackson, S. Lomakin, et al. S. AlMaliaka, A. Golovoy, C.A. Wilkie (Eds.), Chemistry and technology of polymer additives, Blackwell Scientific, London (1998), pp. 249-265

[12] S. Su, D.D. Jiang, C.A. Wilkie. J Vinyl Addit Tech, 10 (2004), pp. 44-51

[13] S. Su, D.D. Jiang, C.A. Wilkie. Polym Degrad Stab, 83 (2004), pp. 321-331 